$01,07,11$

\title{
Особенности отклика церия на импульсные воздействия
}

\author{
(C) С.А. Атрошенко ${ }^{1}$, А.Н. Зубарева ${ }^{2}$, В.А. Морозов ${ }^{3}$, Г.Г. Савенков ${ }^{4}$, А.В. Уткин ${ }^{2}$ \\ ${ }^{1}$ Институт проблем машиноведения РАН, \\ Санкт-Петербург, Россия \\ ${ }^{2}$ Институт проблем химической физики РАН, \\ Черноголовка, Россия \\ ${ }^{3}$ Санкт-Петербургский государственный университет, \\ Санкт-Петербург, Россия \\ ${ }^{4}$ Санкт-Петербургский государственный технологический институт (Технический университет), \\ Санкт-Петербург, Россия \\ E-mail: satroshe@mail.ru
}

(Поступила в Редакцию 12 июля 2017 г.)

\begin{abstract}
Приведены результаты экспериментальных исследований церия при высоких скоростях и наносекундных длительностях воздействия. Проведено исследование изоморфного фазового перехода при ударном сжатии. Определена откольная прочность церия. Обнаружена аномальная сжимаемость церия при динамическом нагружении. Показано затухание волны напряжения при воздействии сильноточного электронного пучка за счет диссипации энергии при фрагментации и двойниковании.
\end{abstract}

Работа выполнялась при финансовой поддержке гранта РНФ 17-11-01053.

DOI: 10.21883/FTT.2018.02.45373.233

\section{1. Введение}

Известно [1], что церий, наиболее распространенный в земной коре и наименее дорогой из редкоземельных элементов, уникален с точки зрения своего необычного электронного строения, которое в конденсированном состоянии проявляется в фазовом многообразии (их у него семь). Церий также относится к небольшому числу веществ, у которых наблюдается протекание изоморфных фазовых превращений [2].

И, наконец, можно отметить следующую особенность церия, а именно: он является немногим примером вещества с аномальной сжимаемостью, которая наблюдается во всей области $\gamma$-фазы $[3,4]$. В целом, подавляющее большинство чистых материалов (веществ) имеют нормальную сжимаемость, и лишь в очень редких случаях у некоторых из них проявляется аномальная сжимаемость. Проявление таких свойств у церия связано с изменениями электронного строения во время $4 f-5 d$-перехода [1].

Что означает аномальная сжимаемость? В большинстве веществ его адиабатическая сжимаемость $\left(\frac{\partial V}{\partial p}\right)_{S}$ снижается с повышением давления, т. е. это означает, что вторая производная положительна

$$
\left(\frac{\partial^{2} V}{\partial p^{2}}\right)_{S}>0 .
$$

Неравенство (1) не является термодинамическим соотношением и может быть нарушено, если поменять знак „>“ на знак „, <“. Такая смена знака и определяет понятие аномальной сжимаемости.

Характер распространения импульса в такой среде принципиально меняется: волна разрежения проявляется как ударная волна, в то время как волна сжатия является изоэнтропической и ее фронт размывается при его распространении по образцу [5].

Несмотря на то что церий является очень удобным материалом для ударно-волновых исследований, направленных на получение прочностных характеристик [3], данных о его свойствах не так много. Следует также отметить, что большинство работ, посвященных динамическому поведению церия, связано с исследованием его свойств в определенных диапазонах давления. И совершенно отсутствуют работы, в которых проводился анализ влияния на его свойства скорости деформации или длительности нагружения.

В связи с этим основная цель настоящей работы заключается в исследовании отклика церия на импульсные воздействия при высоких скоростях деформации и при сверхмалых (наносекундных) длительностях нагружения.

\section{2. Материал и методики проведения экспериментов}

В качестве объекта исследования использовался полученный электролитическим методом церий плотностью $6.75 \mathrm{~g} / \mathrm{cm}^{3}$ и чистотой $99.83 \%$.

Одномерные импульсы сжатия в образцах толщиной 1.5, 2 и $4 \mathrm{~mm}$ и диаметром 30-50 mm создавались металлическими ударниками толщиной 0.4-2.0 mm, метаемыми с помощью различных типов взрывных генераторов ударных волн (рис. 1). Часть экспериментов проводилась с использованием генератора ударных волн малой амплитуды (рис. 1,a). Использование такой схемы нагружения позволяло получить значения давлений ниже 
$a$
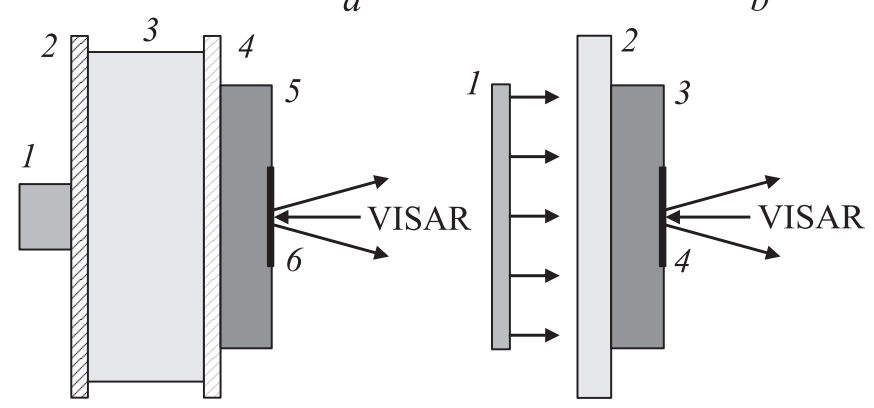

Рис. 1. Схемы экспериментов для исследования параметров ударного сжатия образцов: $a$ ) генератор ударных волн малой

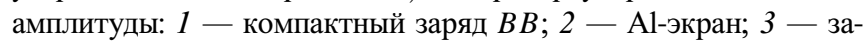
полненный водой контейнер; 4 - плексигласовый экран; 5 образец; 6 - Al-фольга $7 \mu \mathrm{m} ; b)$ „традиционный“ взрывной генератор плоских ударных волн: 1 - ударник; 2 - экран; 3 - образец; 4 - Al-фольга толщиной $7 \mu \mathrm{m}$.

$1 \mathrm{GPa}$. Принцип действия такого генератора основан на затухании ударной волны при прохождении через слой воды. Особенностью данной схемы является формирование ударных волн большой длительности, что позволяет детально изучить структуру фронта ударной волны, но не дает возможности наблюдать поведение материала в волне разгрузки. Поэтому для экспериментов, где требуются более высокие давления нагружения, применяется схема с использованием „традиционного“ взрывного генератора плоских ударных волн, который разгоняет алюминиевые ударники от $0.7 \mathrm{~km} / \mathrm{s}$ (рис. 1,b) [6]. Регистрация профилей скорости свободной поверхности образцов осуществлялась с помощью лазерного доплеровского интерферометра VISAR с постоянной $80.8 \mathrm{~m} / \mathrm{s}$. Это позволило проводить измерения с точностью $2 \mathrm{~m} / \mathrm{s}$ и временным разрешением около $2 \mathrm{~ns}$ [7]. Для отражения зондирующего излучения лазера на свободную поверхность церия наклеивалась алюминиевая фольга толщиной $7 \mu \mathrm{m}$.

Наносекундные длительности нагружения в настоящей работе обеспечивались путем воздействия на мишени из церия сильноточного электронного пучка соответствующей длительности. В случае достаточно высоких значений энергии электронов пучка в мишени при быстром поглощении энергии или объемном разогреве (так называемый тепловой удар) могут возникать волны напряжений высокой интенсивности, которые способны привести к микро- и макроразрушениям, в том числе откольному разрушению. Процесс откольного разрушения под действием быстрого объемного разогрева достаточно хорошо известен, и ему посвящено значительное количество работ (см. обзор в [8]). Можно отметить, что при ударно-волновом нагружении процесс разрушения образцов происходит за времена $t \geq 10^{-8} \mathrm{~s}$, а при тепловом ударе $t \leq 10^{-8} \mathrm{~s}$.

Воздействие на образцы церия (которые играли роль анода) диаметром $20 \mathrm{~mm}$ и толщиной $1.5 \mathrm{~mm}$ производи- лось с помощью экспериментальной установки, включающей электронный ускоритель ГКВИ-300, измерительную аппаратуру, устройства регулирования и контроля условий воздействия сильноточного пучка электронов на образец.

На исследуемые образцы воздействовали сильноточным электронным пучком (СЭП), сформированным в вакуумном диоде ускорителя, с параметрами: средняя энергия электронов - $250 \mathrm{keV}$, длительность импульса тока $-\sim 65 \mathrm{~ns}$, амплитуда тока $-10000 \mathrm{~A}$, мощность потока импульса $-\sim 2.5 \cdot 10^{9} \mathrm{~W} / \mathrm{cm}^{2}$. Регистрация напряжений осуществлялась с помощью пьезодатчика, расположенного на тыльной стороне облучаемого образца.

Поскольку источником СЭП в ускорителе ГКВИ300 является катод взрывоэмиссионного типа, то кроме электронного пучка существенный вклад в разогрев образца вносит катодная плазма (так называемый катодный факел $(К \Phi))$, возникающая при генерации пучка [9]. Импульс напряжения, вызываемый тепловым ударом на поверхности образца КФ, имеет временное запаздывание по отношению к термоупругому импульсу от электронного пучка, определяемое промежутком катод-образец (4 mm в нашем случае) и скоростью движения фронта плазмы ( $145 \mathrm{~km} / \mathrm{s}$ в нашем случае). Суперпозиция обоих импульсов может иметь довольно сложный характер в зависимости от параметров электронного пучка, которые в общем случае имеют вероятностный характер, образца и КФ [10].

\section{3. Результаты ударных экспериментов и их обсуждение}

В таблице представлены экспериментальные параметры и результаты, полученные в экспериментах с церием.

На рис. 2 представлены профили скорости свободной поверхности для образцов церия разной толщины Отчетливо видна двухволновая конфигурация, связанная с $\gamma-\alpha$ фазовым переходом. Наиболее интересным является „размывание“ фронта сжатия по мере распространения по образцу. Это обусловлено аномальной сжимаемостью церия в $\gamma$-фазе, которая приводит к невозможности формирования ударной волны в таких средах, т. е., зарегистрированная волна сжатия является изоэнтропической. В то же время волна разрежения является ударной, что отчетливо видно на профиле 2 (рис. 2, $a$ ).

При давлении ниже фазового перехода двухволновая конфигурация отсутствует (см. рис. 2, $b$ ), но попрежнему наблюдается размытие фронта волны сжатия. Это наиболее отчетливо видно при увеличении толщины образца. Наряду с исследованием $\gamma-\alpha$-фазового перехода, проведены также измерения откольной прочности. Отражение импульса сжатия от свободной поверхности приводит к возникновению растягивающих напряжений внутри образцов, что вызывает их откольное разрушение. 
Параметры экспериментальных сборок и результаты испытаний церия

\begin{tabular}{c|c|c|c|c|c|c}
\hline $\begin{array}{c}\text { № } \\
\text { п/п }\end{array}$ & $\begin{array}{c}\text { Толщина } \\
\text { образца } h l, \mathrm{~mm}\end{array}$ & $\begin{array}{c}\text { Толщина } \\
\text { ударника } h_{l}, \mathrm{~mm}\end{array}$ & $\begin{array}{c}\text { Давление } \\
\text { нагружения } P_{0}, \mathrm{MPa}\end{array}$ & $\begin{array}{c}\text { Откольная } \\
\text { скрость } \Delta W, \mathrm{~m} / \mathrm{s}\end{array}$ & $\begin{array}{c}\text { Откольная } \\
\text { прочность } \sigma_{p}, \text { МРа }\end{array}$ & $\begin{array}{c}\text { Скорость } \\
\text { деформации } \dot{\varepsilon}, \mathrm{s}^{-1}\end{array}$ \\
\hline 1 & 4 & 2 & 3974 & 41 & 265 & $2.1 \cdot 10^{4}$ \\
2 & 1.5 & 0.4 & 2586 & 106 & 687 & $1.02 \cdot 10^{6}$ \\
3 & 1.7 & 0.4 & 1354 & 85.5 & 554 & $3.94 \cdot 10^{5}$ \\
4 & 4 & 0.4 & 785 & 64.5 & 417 & $1.33 \cdot 10^{5}$ \\
5 & 1.8 & 0.4 & 447 & - & - & - \\
6 & 4 & 0.4 & 400 & - & - & -
\end{tabular}

При расчете откольной прочности церия $\sigma_{p}$ использовалась формула для упруго-пластической среды [11]

$$
\sigma_{p}=\rho_{0} \frac{c_{0} c_{l}}{c_{0}+c_{l}} \Delta W
$$

где $c_{l}=2.23 \mathrm{~km} / \mathrm{s}$, измеренная ультразвуковым методом продольная скорость звука; $c_{0}=1.68 \mathrm{~km} / \mathrm{s}$, объемная скорость звука [12]; $\Delta W$ - разница скоростей („откольная“ скорость) между максимальным и минимальным значениями скорости свободной поверхности перед откольным импульсом.
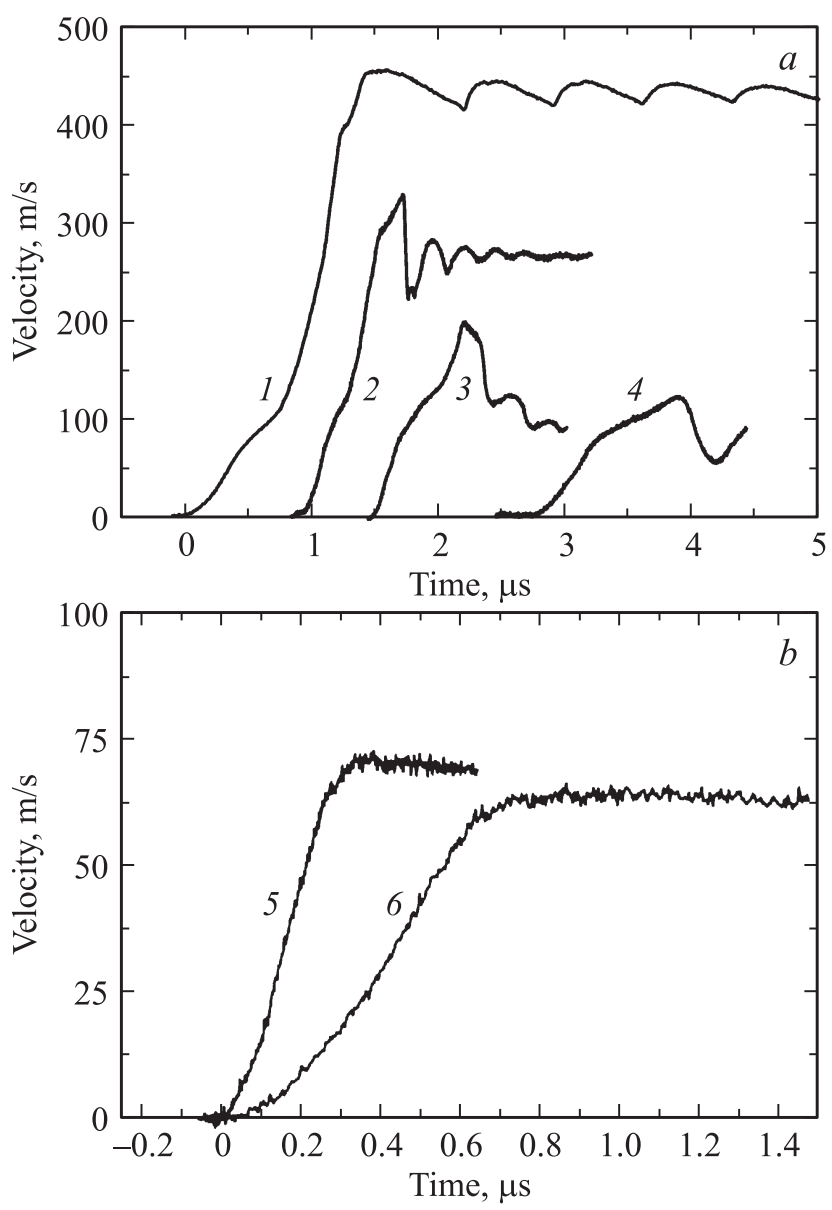

Pис. 2. Экспериментальные результаты для церия (цифры на профилях соответствуют номерам экспериментов в таблице).
В таблице приведены полученные значения откольной прочности и скорости деформации в разгрузочной части импульса $\dot{\varepsilon}=(d W / d t) / 2 c_{0}$, между которыми была обнаружена сильная зависимость. Было установлено, что при увеличении скорости от $2.1 \cdot 10^{4}$ до $1.02 \cdot 10^{6} \mathrm{~s}^{-1}$, откольная прочность возрастает от 0.3 до $0.7 \mathrm{GPa}$. Можно отметить, что полученные значения откольной прочности в целом весьма невелики и соответствуют значениям откольной прочности для хрупких материалов, например для алюминиевой керамики $\mathrm{Al}_{2} \mathrm{O}_{3} \sigma_{p} \approx 600 \mathrm{MPa}$ [13].

Как было показано выше, двухволновая конфигурация профиля скорости для церия может быть вызвана фазовым переходом. Следует отметить, что переход от $\gamma$ к $\alpha$-фазе на профиле скорости свободной поверхности является настолько плавным (например, профиль 1 на рис. 2,a), что невозможно однозначно определить с хорошей точностью давление фазового перехода. Одной из причин этого является переотражение первой волны в результате ее циркуляции между свободной поверхностью и ударной волной, соответствующей $\alpha$-фазе. Из-за циркуляции волны профиль сглаживается, что приводит к исчезновению излома на профиле скорости, который следовало бы ожидать в результате фазового перехода. Примерное расположение точки излома можно определить, экстраполируя зависимость скорости свободной поверхности от времени на участках профиля, которые соответствуют $\gamma$ и $\alpha$-фазам. В результате такой экстраполяции (профиль 3, рис. 2), можно получить точку пересечения, которая и дает положение фазового перехода, равное $155 \pm 5 \mathrm{~m} / \mathrm{s}$.

Для определения давления фазового перехода используем тот факт, что процесс сжатия является изоэнтропическим. Поэтому, если фронт входящей в образец ударной волны можно рассматривать как скачок, то должна формироваться центрированная волна сжатия, аналогично формированию центрированной волны разрежения в средах с нормальной сжимаемостью. Для проверки этого предположения представленные на рис. 2, $a$ волновые профили были перестроены в координатах $t / h$ (рис. 3), где $t-$ время, $h-$ толщина образца. Видно, что профили скорости практически совпадают, т.е. течение автомодельно, и волна сжатия действительно является центрированной. Это позволяет на основании 


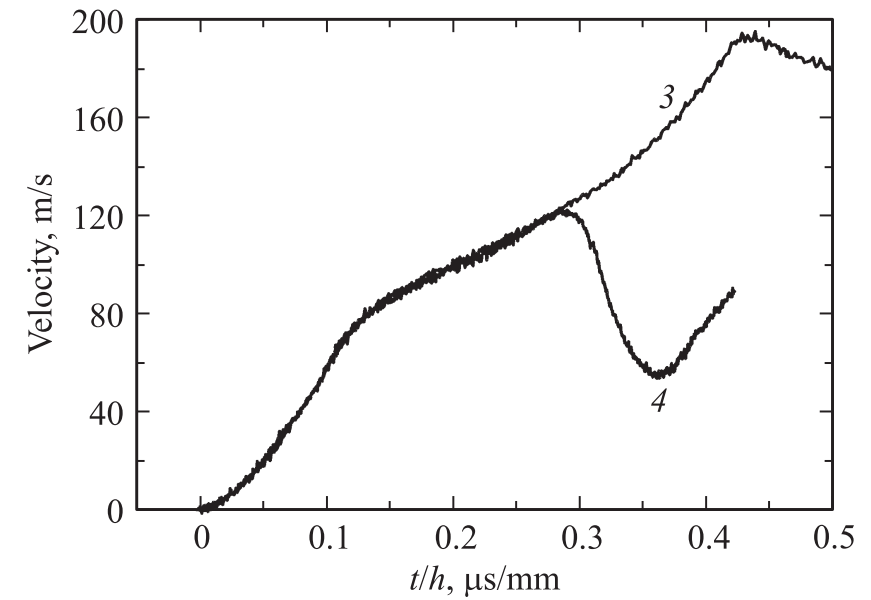

Рис. 3. Профили скорости свободной поверхности церия в приведенных координатах.

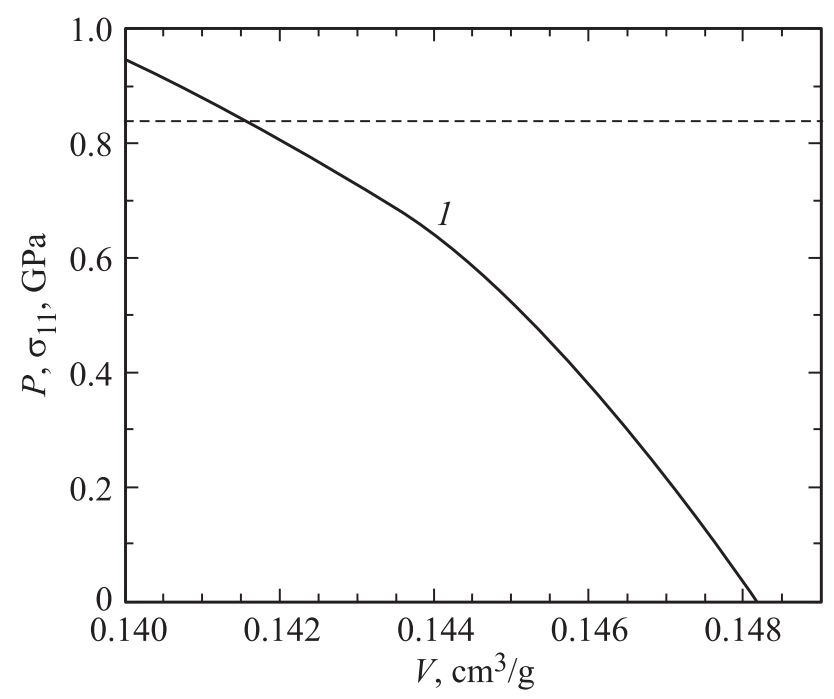

Рис. 4. Изоэнтропа сжатия церия в $\gamma$-фазе.

полученных экспериментальных данных рассчитать изоэнтропу сжатия.

Из условия сохранения инвариантов Римана [14] следует постоянство скорости звука вдоль характеристик, поэтому они представляют собой пучок прямых линий. Это позволяет рассчитать лагранжеву скорость звука $a_{L}$ на каждой характеристике, зная время ее выхода на свободную поверхность $t_{f}$

$$
a_{L}=\frac{h}{t_{f}+h / c_{l 0}}
$$

где $c_{l 0}-$ скорость звука при нулевом давлении.

Поскольку массовая скорость $u$, равная половине скорости свободной поверхности, в каждый момент времени известна, то получаем зависимость $a_{L}$ от $u$. Зная зависимость скорости звука от массовой скорости, можно найти изоэнтропу сжатия в плоскости давление $P-$ удельный объем $V$. Для этого используем условие посто- янства инвариантов Римана вдоль характеристик [14]

$$
d P=\rho_{0} a_{L} d u, \quad d V=\frac{d u}{\rho_{0} a_{L}}
$$

из которого непосредственно получаем давление и удельный объем как функции массовой скорости. Исключая $u$, находим изоэнтропу $P(V)$, которая представлена на рис. 4.

Видно, что изоэнропа имеет отрицательную кривизну, как и должно быть для сред с аномальной сжимаемостью. Пунктиром указано давление фазового перехода, известное из статических экспериментов при комнатной температуре.

\section{4. Результаты воздействия на образцы электронного пучка. Металлография образцов. Обсуждение результатов}

Удар по образцам СЭП и последующее воздействие на них катодного факела не приводило к регистрации датчиком давления какого-либо отклика (рис. 5). Полученные результаты свидетельствовали, что возникающая на фронтальной поверхности волна смещения (напряжения) интенсивно затухает и не доходит до тыльной поверхности.

Предварительный анализ имеющейся информации в различных источниках показал, что аналогичный эффект быстрого затухания на расстояниях $\sim 1 \mathrm{~mm}$ наносекундных импульсов сжатия, возбуждаемых лазерным излучением [15] и сильноточным электронным пучком [16], наблюдается в металлах, предел упругости которых сравним с амплитудой самого импульса. В нашем случае амплитуда динамических напряжений также невелика и составляет $\sigma_{d} \approx \Gamma \Delta E=600-700 \mathrm{MPa}[17]$ ( $\Gamma-$ коэффициент Грюнайзена, $\Delta E-$ объемная плотность поглощенной энергии). С учетом того, что откольная

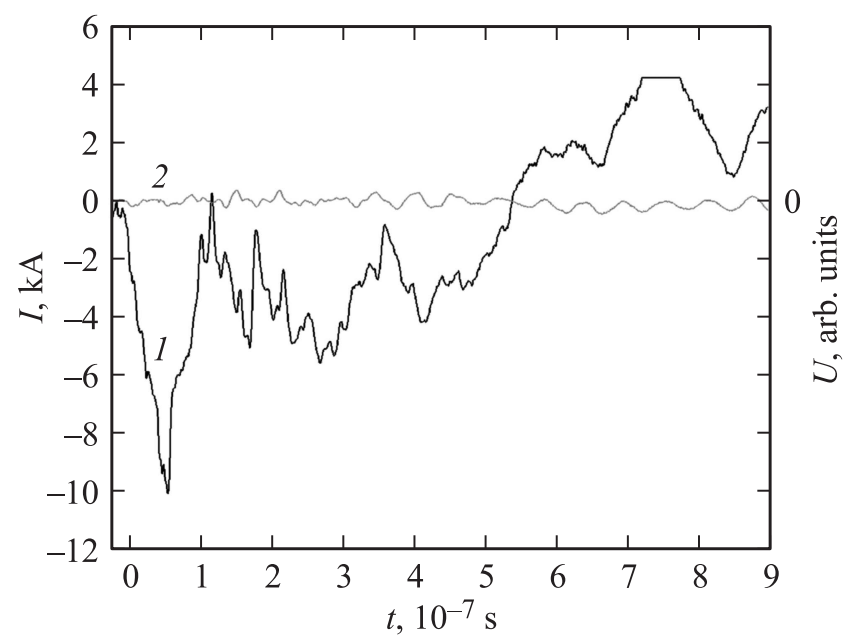

Рис. 5. Осциллограмма тока $(1)$ и сигнал с датчика давления (2). 
прочность практически совпадает с истинным динамическим пределом прочности (который для хрупких материалов не намного выше предела упругости) [18], мы имеем то же самое условие сопоставимости предела упругости и амплитуды импульса сжатия, что и в $[15,16]$. В [15] аномальную эволюцию импульса сжатия объяснили влиянием догоняющей упругой разгрузки, а в [16] - высокой скоростью ввода энергии в материал и, как следствие, сильно неравновесным процессом в приповерхностной области нагружения.

Кроме того, затухание упругой волны сжатия может быть вызвано: рассеянием энергии волны на дефектах [19] и границах зерен [20], поглощением энергии на сингулярных линиях (микротрещинах) [21] и другими эффектами [22].

С целью ответа на вопрос, с чем связано столь быстрое затухание волны напряжения в нашем случае, были проведены металлографические исследования облученных образцов.

На рис. 6-8 последовательно представлены: поверхностный слой (рис. 6,a), следующая за ним область высокой концентрации микромезотрещин (рис. 6, b), область фрагментированных зерен (рис. 7) и центральная (на середине толщины) область образца (рис. 8).

На рис. 6, $a$ виден слабо травящийся (или практически не травящийся) светлый поверхностный слой толщиной $80-160 \mu \mathrm{m}$. Этот участок в результате первичного воз-
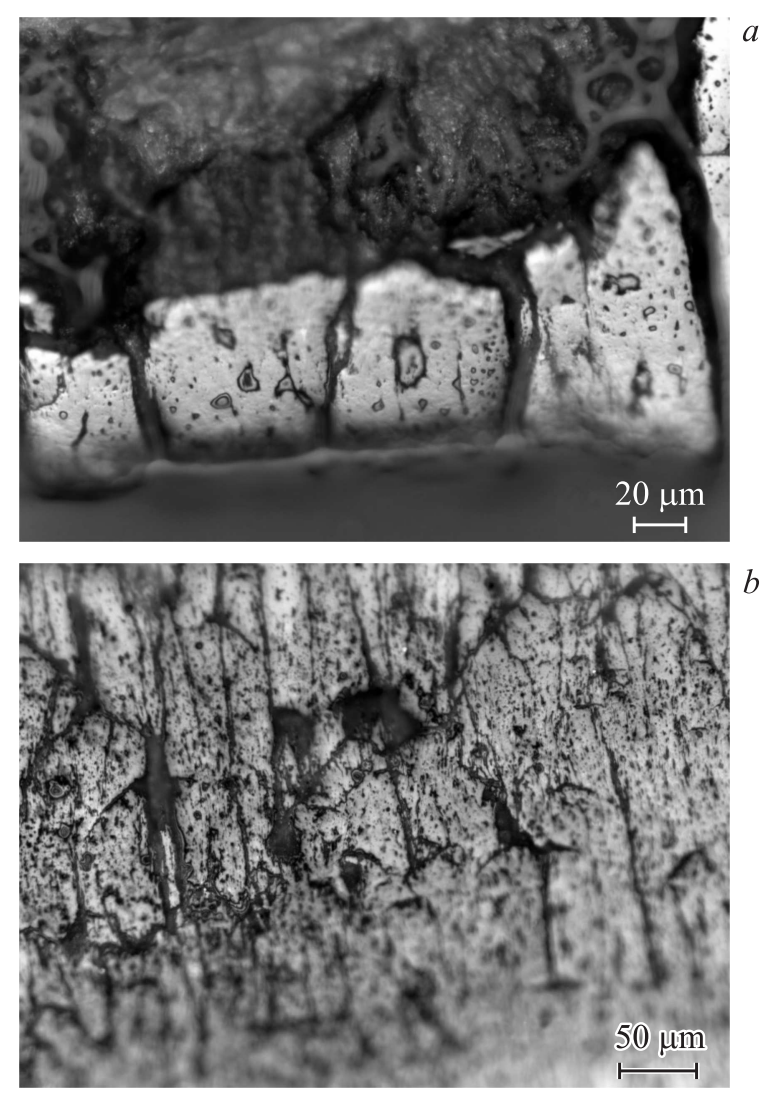

Рис. 6. Приповерхностный слой образца (мишени).

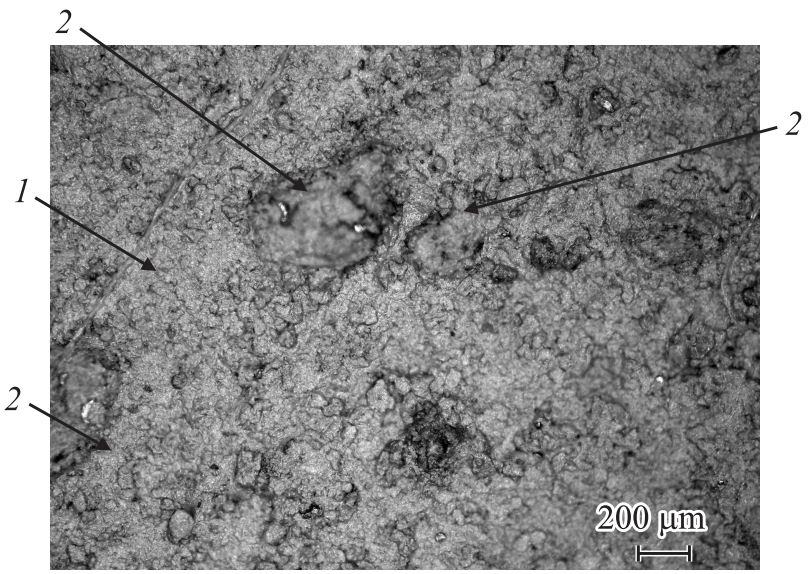

Рис. 7. Область фрагментации зерен (1 - полоса локализованного сдвига, 2 - микрофрагментированные области, окружающие крупные зерна).
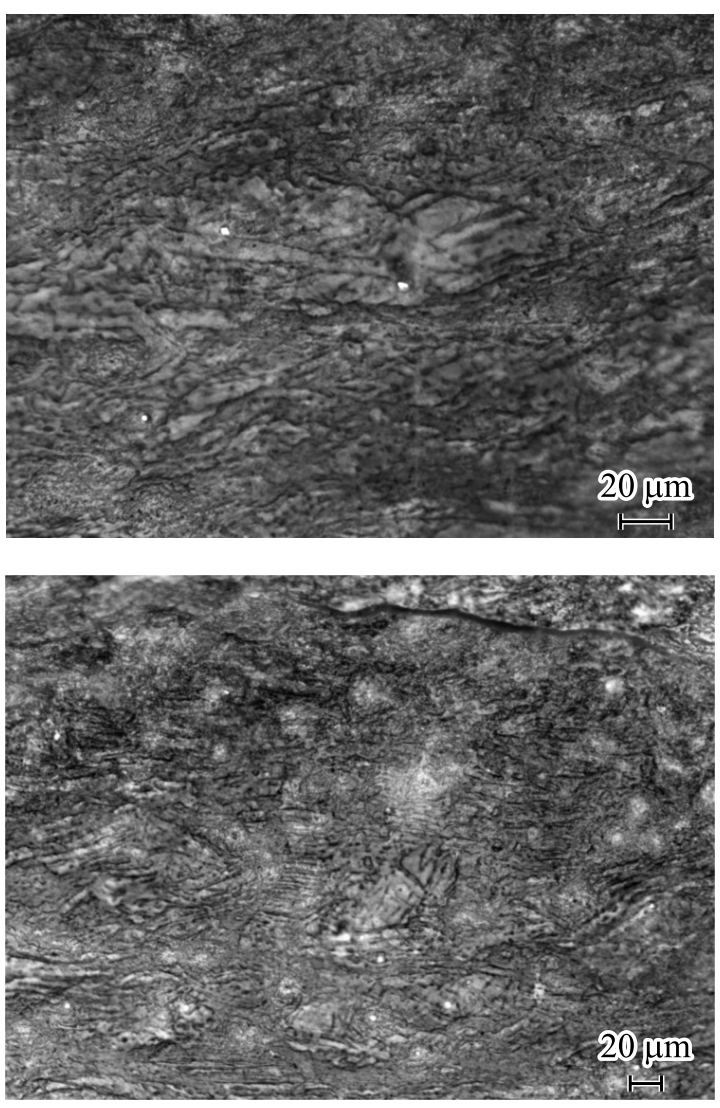

Рис. 8. Структура образцов церия в центре шлифа.

действия электронного пучка и вторичного воздействия плазмой катодного факела подвергся быстрому нагреву и быстрому охлаждению, что привело к образованию мелкокристаллической, а в некоторых случаях и аморфной структуры в слое. Одновременно повышение давления привело к изоморфному фазовому превращению $(\gamma \rightarrow \alpha)$. 
На рис. 7 представлена область фрагментированных зерен, размер которых находится в диапазоне $30-40 \mu \mathrm{m}$, что в два раза меньше исходного [23]. На этом же рисунке представлены полоса локализованного сдвига (1) и микрофрагментированные области (2), окружающие крупные округлые зерна, также разбитые на микрофрагменты. Выявленные особенности микроструктуры на данном участке дают основание полагать, что вышеуказанные структурные элементы характеризуют очаг микропластической деформации в момент прохождения волны напряжения, созданной импульсным электронным пучком. В этой области образца микропластическая деформация реализовалась с участием трансляционных и ротационным мод деформации в форме вихревого механического поля.

На рис. 8 представлена структура центральной области образца. В данной области находится большое количество двойников, типичных для пластической деформации при высокоскоростном нагружении [24].

В целом проведенные металлографические исследования позволяют предполагать, что аномальное затухание волн напряжений, вызванных действием импульсного электронного пучка и катодного факела, связано с диссипацией энергии, идущей на структурные преобразования (фрагментация и двойникование). Данное предположение согласуется с выводами работы [25] о том, что на временах микросекундного диапазона длительностей нагружения и короче $65-70 \%$ внешней энергии, приложенной к деформируемому материалу, расходуется на структурообразование.

Другим фактором, влияющим на затухание волны, является поглощение ее энергии микромезотрещинами, образующимися по механизму „встречного“ разрушения [26]. Механизм встречного разрушения заключается в том, что на некотором расстоянии от вершины образующегося под действием волны напряжения дефекта зарождается микротрещина, которая может опережать волну напряжения, а затем и ослаблять ее.

\section{5. Заключение}

На основании проведенных исследований можно сделать следующие выводы.

1. Установлено, что при ударном нагружении образцов церия образуется двухволновая конфигурация, связанная с $\gamma-\alpha$ фазовым переходом. При этом наблюдается размывание фронта сжатия по мере его распространения по образцу.

2. Полученная расчетно-экспериментальным методом изоэнтропа сжатия церия имеет отрицательную кривизну, что связано с его аномальной сжимаемостью.

3. Установлено, что при воздействии на образцы церия сильноточного электронного пучка и катодного факела наблюдается интенсивное затухание волны напряжения, возникающей вследствие быстрого поглощения энергии.
4. Интенсивное затухание волны напряжения может быть связано со структурообразованием в церии и поглощение ее энергии микромезотрещинами, образующимися по механизму „встречного“ разрушения.

\section{Список литературы}

[1] А.В. Николаев, А.В. Цвященко. УФН 182, 7, 701 (2012).

[2] М.Н. Павловский, В.В. Комиссаров, А.Р. Кутсар. ФГВ 35, 1, 98 (1999).

[3] М.В. Жерноклетов, А.Е. Ковалев, В.В. Комиссаров, М.Г. Новиков, М.Э. Зохер, Ф.Д. Чернее. ЖЭТФ 139, 2, 249 (2011).

[4] В.М. Елькин, Е.А. Козлов, Е.В. Какшина, Ю.С. Морева. ФММ 101, 3, 232 (2006).

[5] Л.Д. Ландау, Е.М. Лифшиц. Теоретическая физика: Гидродинамика. Наука, М. (1986). T. VI. 736 с.

[6] Г.И. Канель, С.В. Разоренов, А.В. Уткин, В.Е. Фортов. Ударно-волновые явления в конденсированных средах. Янус-К, М. (1996). 406 с.

[7] L.H. Barker, R.E. Hollenbach. J. Appl. Phys. 45, 11, 4872 (1974).

[8] С.А. Новиков, А.И. Рузанов, И.Р. Трунин, А.Я. Учаев. Проблемы прочности 2, 61 (1994).

[9] Г.А. Месяц. Эктоны. Ч. 1. Взрывная эмиссия электронов. УИФ, Екатеринбург (1993). 184 с.

[10] Ю.И. Мещеряков, В.А. Морозов. ЖТФ 49, 9, 1982 (1979).

[11] Г.В. Степанов. Проблемы прочности 8, 66 (1976).

[12] F. Decremps, D. Antonangeli, B. Amadon, G. Schmerber. Phys. Rev. B 80, 132103 (2009).

[13] А.М. Брагов, Л.А. Игумнов, А.К. Ломунов. Высокоскоростная деформация мелкозернистого бетона и фибробетона. Изд-во ННГУ, Нижний Новгород (2015). 270 с.

[14] Физика взрыва / Под ред. Л.П. Орленко. Т. 1. Физматлит, M. (2002). 832 c.

[15] Б.М. Жиряков, В.Г. Малинин, В.Ф. Обеснюк. Проблемы прочности 3, 56 (1986).

[16] В.А. Морозов. XIV Междунар. шк. по моделям механики сплошной среды. Сб. докл. МФТИ, М. (1997). С. 105-117.

[17] В.А. Морозов, Г.Г. Савенков, В.А. Брагин, В.М. Кац, А.А. Лукин. ЖТФ 82, 5, 129 (2012).

[18] Г.Г. Савенков. Прикладная механика и техническая физика 46, 6, 103 (2005).

[19] И.А. Кунин. Теория упругих сред с микроструктурой. Наука, М. (1975). 416 с.

[20] В.М. Баранов, А.И. Гриценко, А.М. Карасевич. Акустическая диагностика и контроль на предприятиях топливноэнергетического комплекса. Наука, М. (1998). 304 с.

[21] В.Б. Поручиков. Методы динамической упругости. Наука, М. (1986). $328 \mathrm{c}$.

[22] Л.Д. Ландау, Е.М. Лифшиц. Теория упругости. Наука, М. (1987). $248 \mathrm{c}$.

[23] М.А. Филянд, Е.И. Семенова. Свойства редких элементов. Справочник. Металлургия, М. (1964). 913 с.

[24] Г.Н. Эпштейн. Строение металлов, деформированных взрывом. Металлургия, М. (1988). 280 с.

[25] Ю.И. Мещеряков. Физическая мезомеханика 8, 6, 5 (2005).

[26] А.Я. Красовский, Г. Плювинаж. Проблемы прочности 1 , 18 (1994). 